\title{
Restoration of Nusinersen Levels Following Treatment Interruption in People With Spinal Muscular Atrophy: Simulations Based on a Population Pharmacokinetic Model
}

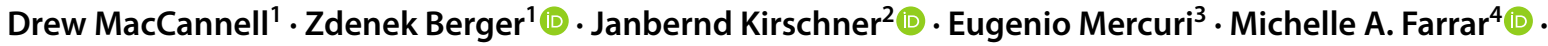 \\ Susan T. Iannaccone ${ }^{5} \cdot$ Nancy L. Kuntz $^{6}\left(\mathbb{D} \cdot\right.$ Richard S. Finkel $^{7} \cdot$ Marta Valente $^{8} \cdot$ Francesco Muntoni $^{9}$ (i)
}

Accepted: 11 January 2022 / Published online: 26 January 2022

(c) The Author(s) 2022

\begin{abstract}
Background Nusinersen is approved for the treatment of spinal muscular atrophy. The most common approved dosing regimen is four intrathecal loading doses of nusinersen $12 \mathrm{mg}$; the first three are administered at 14-day intervals followed by a fourth dose 30 days later, and then 12-mg maintenance doses are administered every 4 months thereafter. Interruption of nusinersen treatment in the maintenance dosing phase might occur for a number of clinical reasons.

Objective The objective of this report is to describe dosing regimens that allow for the most rapid restoration of steady-state concentrations of nusinersen in the cerebrospinal fluid (CSF) following a treatment interruption during maintenance dosing. Methods Population pharmacokinetic models using integrated pharmacokinetic data from ten nusinersen clinical trials that included a broad range of participants with spinal muscular atrophy treated with intrathecal nusinersen were used to investigate different durations of treatment interruptions during maintenance treatment. Potential dosing regimens for reinitiation of nusinersen were evaluated, with the goal of achieving the quickest restoration of steady-state nusinersen CSF concentrations without exceeding maximal CSF exposures observed during the initial loading period.

Results Our pharmacokinetic modeling indicates the following regimen will lead to optimal restoration of nusinersen CSF levels after treatment interruption: two doses of nusinersen should be administered at 14-day intervals following treatment interruptions of $\geq 8$ to $<16$ months since the last dose, and three doses of nusinersen at 14-day intervals for treatment interruptions of $\geq 16$ to $<40$ months since the last maintenance dose, with subsequent maintenance dosing every 4 months in both instances. After treatment interruptions of $\geq 40$ months, the full loading regimen will rapidly restore nusinersen CSF levels. Conclusions Prolonged treatment interruptions lead to suboptimal CSF levels of nusinersen. The optimal regimen to restore nusinersen CSF levels depends on the interval since the last maintenance dose was administered.
\end{abstract}

\section{Plain Language Summary}

Nusinersen is a drug used to treat people of all ages who have spinal muscular atrophy. Nusinersen is injected with a thin needle into the lower back, a procedure known as a lumbar puncture. People initially receive three doses of nusinersen $12 \mathrm{mg}$ each 14 days apart. They receive a fourth dose 1 month later, and then injections every 4 months (known as maintenance dosing). This treatment plan allows nusinersen to build up to effective levels in the fluid surrounding the spinal cord and brain. Some people may miss dose(s) or may stop nusinersen treatment at some point during maintenance dosing and then may want to continue treatment. This study used information from ten clinical trials to find out the best way to restart treatment to build up nusinersen to effective levels. People with a treatment break of $\geq 8$ to $<16$ months since the last dose need two doses of nusinersen at 14-day intervals before receiving maintenance dosing. People with a treatment break of $\geq 16$ to $<40$ months since the last dose need three doses of nusinersen at 14-day intervals before receiving maintenance dosing. If people stopped treatment for $\geq 40$ months, they would need four doses before starting maintenance treatment. Results from this study showed that the number of doses that people needed before starting maintenance treatment depended on how long the treatment break was.

Zdenek Berger

zdenek.berger@biogen.com

Extended author information available on the last page of the article 


\section{Key Points}

Treatment interruptions lead to lower levels of nusinersen, which may impact efficacy.

Based on pharmacokinetic modeling, the optimal regimen to restore nusinersen cerebrospinal fluid (CSF) levels depends on the interval since the last maintenance dose was administered. For the interval of $\geq 8$ to $<16$ months since the last dose, two doses of nusinersen at 14-day intervals will rapidly restore nusinersen CSF levels. For the interval of $\geq 16$ to $<40$ months since the last dose, three doses of nusinersen 14 days apart will rapidly restore nusinersen CSF levels. For treatment interruptions of $\geq 40$ months, the full four-dose loading dose regimen will rapidly restore nusinersen CSF levels.

The proposed dosing regimens will lead to rapid restoration of levels of nusinersen in CSF similar to those expected without any interruption in dosing. As the levels of nusinersen attained are similar to those with the standard regimen, no new safety issues are expected.

\section{Introduction}

Spinal muscular atrophy (SMA) is an autosomal recessive neuromuscular disease characterized by muscle weakness $[1,2]$ that affects children and adults, with an estimated incidence of one in 10,000 live births [2,3]. Mutations or deletions in the survival motor neuron 1 (SMNI) gene result in a deficiency of the SMN protein, which predominantly affects the alpha motor neurons in the spinal cord and causes degeneration and progressive muscular atrophy $[1,2,4,5]$. Individuals with SMA have at least one copy of the paralogous SMN2 gene, which also encodes the SMN protein; however, a single nucleotide transition alters splicing such that the majority of SMN2 messenger RNA (mRNA) transcripts exclude exon 7 and the resultant protein is unstable and degraded [5]. The low levels of SMN2-encoded fulllength SMN protein do not adequately compensate for the loss of SMN1 [2, 5].

Spinal muscular atrophy disease severity is generally inversely correlated with the $S M N 2$ gene copy number, and individuals with a higher number of $S M N 2$ gene copies typically have less severe disease [1]. Although the phenotype of SMA is now understood to span a broad continuum, this disease has traditionally been classified into subtypes based on age at onset and maximum motor function attained with supportive care $[1,6]$. Spinal muscular atrophy type I is the most severe form, with onset before the age of 6 months and death typically occurring at $<2$ years of age $[5,7]$. In SMA types II, III, and IV, symptoms are less severe but remain debilitating, and occur later in life (at age 6-18 months for type II, at age 1.5-10 years for type III, and in adulthood for type IV) [6].

In recent years, survival rates for the severe forms of SMA have substantially increased, and progression of all types can now be slowed with the advent of successful therapeutic approaches and improvements in standard of care $[8,9]$. The antisense oligonucleotide drug nusinersen (Spinraza ${ }^{\circledR}$ ) is the first approved treatment for SMA [10, 11]. Nusinersen alters the splicing of $S M N 2$ precursor mRNA and increases inclusion of exon 7 in the mature mRNA transcripts, ultimately increasing production of full-length SMN protein [12-14]. Nusinersen has been evaluated in a clinical development program including studies of symptomatic infantile-onset SMA [15-17] and symptomatic later-onset SMA [17-20], including long-term follow-up in these populations [21, 22], as well as in presymptomatic infants genetically diagnosed with 5q SMA [23]. Nusinersen has demonstrated clinically meaningful efficacy and a favorable risk-benefit profile in a broad range of individuals with SMA in clinical studies and real-world populations, including in adults $[15-17,19,20$, 23-31]. Nusinersen is administered intrathecally at doses of $12 \mathrm{mg}$. The most common approved dosing regimen comprises four loading doses; the first three are administered at 14-day intervals followed by a fourth dose 30 days later, and maintenance doses administered every 4 months thereafter $[10,11]$.

We previously reported [32] two scenarios of dosing delays during the maintenance regimen: a short delay (defined as $<4$ months) and one missed maintenance dose. If a delay in administration occurs, nusinersen levels will be restored rapidly by administering the delayed dose as soon as possible and then administering the subsequent dose as previously scheduled. If one maintenance dose is missed, nusinersen levels will be restored most rapidly by administering the missed dose as soon as possible, followed by an additional dose 14 days later [32].

The objective of this report is to describe dosing regimens that allow for the most rapid restoration of steady-state concentrations of nusinersen in the cerebrospinal fluid (CSF) following treatment interruptions during the maintenance phase of $>8$ months since the last maintenance dose. A longer treatment interruption may occur in the context of clinical practice for a number of reasons, such as the ongoing COVID-19 pandemic, pregnancy/childbirth, or changing therapy and subsequently returning to nusinersen. Similar to our previous report [32], this analysis is based on a population pharmacokinetic (PK) model, given the limited data from clinical trials on dosing delays. Because of the different potential reasons for treatment interruptions, all 
dosing intervals are expressed as time since the last dose was administered.

\section{Methods}

\subsection{Population PK Model}

The population PK model was based on CSF and plasma from nusinersen clinical trials [15-20, 23]. In brief, the population PK analysis used nusinersen plasma and CSF concentration data from participants in ten nusinersen clinical trials that had different doses and dosing regimens of intrathecally administered nusinersen [32]. Participants included children and adolescents with later-onset SMA, infants with infantile-onset SMA, and presymptomatic infants who were genetically diagnosed with SMA at study start. Nusinersen plasma and CSF concentration measurements, as well as the dose and time at which those measurements were taken, were integrated into a single dataset incorporating all PK data from the ten trials.

In summary, the model is a four-compartment PK model where nusinersen is administered directly to the CSF compartment (with a predicted volume of distribution of 0.391 L). After administration, it equilibrates to tissues adjacent to the CSF and irreversibly drains to the plasma compartment (predicted to have a volume of distribution of $39.3 \mathrm{~L}$ ). Within the plasma compartment, nusinersen also equilibrates with tissues adjacent to plasma, and is finally cleared from the body. Drainage from the CSF compartment to plasma is predicted to occur at an approximate rate of $0.158 \mathrm{~L} / \mathrm{h}$, resulting in an approximate half-life in the CSF of 4 months. Drainage from CSF and equilibration with adjacent tissues results in a similar half-life in plasma, despite more rapid clearance. Body weight was identified as a relevant covariate in the CSF volume of distribution at body weights $<20 \mathrm{~kg}$ (but with only minimal effect on CSF trough concentration $\left.\left[C_{\text {trough }}\right]\right)$, in the volume of distribution of plasma, and in the clearance rate from plasma. This results in a stable CSF exposure across a wide range of body weights, while the exposure in the plasma compartment reduces significantly as body weight increases. The detailed results from the model parameters have been reported previously [32].

\subsection{Simulation of Dosing Interruptions}

\subsubsection{General Principles for Modeling Treatment Interruptions}

Simulations of treatment interruptions were performed in accordance with previously published analyses that evaluated shorter delays in nusinersen dosing during the loading or maintenance phases [32]. The Fisher information matrix and the interindividual variability measures of all relevant parameters were sampled to produce an ensemble of 10,000 unique parameter sets. Each parameter set was subjected to a different dosing regimen that deviated from the accepted label regimen in several distinct ways. The duration of dosing interruption and the phase at which that interruption occurred were immediately identified as critically impactful on nusinersen exposure in CSF. Therefore, variations on the approved label dosing regimen were selected to interrogate delays in dosing of variable duration during the maintenance phase of treatment. Delays of 4-40 months during the maintenance phase were investigated, as was the time taken for CSF $\mathrm{C}_{\text {trough }}$ (the lowest CSF concentration before the next dose) to achieve a desired level. We evaluated several scenarios to identify those that rapidly produced desired nusinersen CSF levels (steady-state CSF trough concentration without interruption: $5.33 \mathrm{ng} / \mathrm{mL}$ ) without exposing patients to nusinersen CSF levels higher than those previously attained during the initial loading phase of treatment $(8.32 \mathrm{ng} / \mathrm{mL})$. To achieve this, we investigated whether additional doses would be necessary to restore CSF $C_{\text {trough }}$ to a level similar to those predicted had the interruption not occurred (i.e., steady-state CSF nusinersen concentrations). The intervals between doses were based on what was studied in the clinical development plan and are part of the loading phase of the approved dosing regimen (three doses 14 days apart, with a subsequent dose 30 days later).

\subsubsection{Modeling Specific Treatment Interruptions}

To build on the previously published analysis [32], which showed that administration of one missed dose as soon as possible and one additional dose 14 days later will restore steady-state concentrations of nusinersen 8 months since the last dose (i.e., one missed dose), we ran simulations to determine the maximum length of the interval since the last dose that this regimen would be sufficient to appropriately restore nusinersen CSF levels (i.e., similar to steady state without interruptions, but always below CSF levels reached during loading). Beyond this interval (16 months, as described in results), this dosing regimen was not sufficient to restore nusinersen levels and we, therefore, added one additional dose (i.e., dosing 0 , 14 , and 28 days after treatment is restored), followed by every 4-month dosing thereafter and modeled this regimen until 40 months (which restores CSF nusinersen levels as described in the results section). After a 40-month interruption, little nusinersen remains either in the CSF or in other relevant biological matrices. We, therefore, simulated the entire loading regimen (i.e., dosing 0,14 , 28 , and 58 days after restoration of treatment). Over the longest 40-month period, CSF trough concentration 
decays exponentially to a value of approximately $0.07 \mathrm{ng} /$ $\mathrm{mL}$ (95\% prediction interval: $0.02-0.20 \mathrm{ng} / \mathrm{mL}$; Table 1 ). As a consequence, the full loading regimen results in a maximum $C_{\text {trough }}$ that is nearly indistinguishable from the initial loading phase $(8.40 \mathrm{ng} / \mathrm{mL}$ [95\% prediction interval: $5.00-13.66 \mathrm{ng} / \mathrm{mL}$; Table 1] vs $8.32 \mathrm{ng} / \mathrm{mL}$ [95\% prediction interval: $4.82-13.48 \mathrm{ng} / \mathrm{mL}]$ ).

Exposures of nusinersen in plasma were modeled with all scenarios and the plasma exposures achieved after these additional doses did not exceed those predicted during the initial loading phase. In this report, we focus on nusinersen levels in the CSF (surrogate for central nervous system levels) because SMA is a disease characterized by a loss of motor neurons in the spinal cord [ 1 , $2,4]$. Nusinersen is administered intrathecally, directly to the central nervous system, so that nusinersen can bind $S M N 2$ precursor mRNA to increase SMN protein levels in the target tissue affected in this disease [12-14].

\subsection{Data Analysis and Graphing Software}

NONMEM $^{\circledR}$ Version 7.3 and Perl-speaks-NONMEM Version 4.6.0 (ICON Development Solutions, Ellicott City, MD, USA) were used for the nusinersen population PK analysis. R software ( $\mathrm{R}$ version 3.6.4, $\mathrm{R}$ Foundation for Statistical Computing, Vienna, Austria) was used for data handling and $\mathrm{R}$ version 3.6.4 along with ggplot2 [33] version 3.3.5 were used for plotting.

\section{Results}

\subsection{Time Since Last Dose: $\geq 8$ to $<16$ Months}

To build on the previously published analysis of short treatment interruptions [32], we found using the PK model that administration of one missed dose as soon as possible and one additional dose 14 days later will restore steady-state CSF concentrations of nusinersen until 16 months since the last maintenance dose (Fig. 1) (i.e., up to three missed doses, for additional details, see Sect. 2.2.2). As an example, Fig. 2 illustrates levels of nusinersen in CSF (trough concentrations) when two maintenance doses are missed and an additional dose is administered 12 months after the last dose. In this case, administering an additional dose will restore steady-state nusinersen CSF concentrations approximately 19.5 months earlier (Fig. 2b) compared with resuming the maintenance dosing with one maintenance dose and then administering nusinersen at 4-month intervals (Fig. 2a).

\subsection{Time Since Last Dose: $\geq 16$ to $<40$ Months}

When the time since the last dose reached 16 months, our PK model shows that administration of the missed dose as soon as possible, the next dose 14 days later, and then a third dose 14 days later is needed to restore CSF steady-state concentrations of nusinersen (Fig. 3, for additional details, see Sect. 2.2.2). Our analysis indicates that this regimen will restore steady-state concentrations up to 40 months since the last dose. As an example, Fig. 3 shows nusinersen CSF levels (trough concentration) after administration of a single dose 16 months after the last dose, followed by maintenance dosing every 4 months, which results in suboptimal nusinersen CSF levels (trough concentrations) for approximately 20 months (Fig. 3a). In contrast, the nusinersen CSF levels will be restored after the third dose (i.e., approximately 19 months earlier) if two additional doses are administered, separated by 14 days (i.e., total of three doses each 14 days apart) [Fig. 3b].

\subsection{Time Since Last Dose: $\geq \mathbf{4 0}$ Months}

Our analysis indicated that administering the entire loading regimen $\geq 40$ months ( $\geq 3.3$ years) since the last dose will restore nusinersen CSF levels (trough concentrations)

Table 1 Median CSF $C_{\text {trough }}$ after treatment interruption, and maximum CSF $C_{\text {trough }}$ after the dosing regimen to restore nusinersen levels following treatment interruptions of 8,16 , or 40 months

\begin{tabular}{lll}
\hline Time since last dose, months & $\begin{array}{l}\text { Median CSF } C_{\text {trough }} \text { after treatment interruption (95\% PI), } \\
\text { ng/mL }\end{array}$ & $\begin{array}{l}\text { Maximum CSF } C_{\text {trough }} \text { after dosing } \\
\text { regimen to restore levels }{ }^{\mathrm{a}}(95 \% \text { PI), } \\
\text { ng/mL }\end{array}$ \\
\hline 8 & $3.36(1.79-3.46)$ & $6.34(3.60-11.09)$ \\
16 & $2.06(1.07-4.42)$ & $7.26(4.27-12.46)$ \\
40 & $0.07(0.02-0.20)$ & $8.40(5.00-13.66)$ \\
\hline
\end{tabular}

The maximum $C_{\text {trough }}$ during the initial loading phase is predicted to be 8.32 (95\% PI: 4.82-13.48) ng/mL. Steady-state $C_{\text {trough }}$ is predicted to be 5.33 (95\% PI: $2.74-9.75) \mathrm{ng} / \mathrm{mL}$. $C_{\text {trough }}$ CSF levels are $\sim 8600$-fold lower than $C_{\text {max. }}$ The model predicts that CSF $C_{\max }$ should never exceed that experienced during the initial loading phase

CSF cerebrospinal fluid, $C_{\max }$ maximum concentration, $C_{\text {trough }}$ trough concentration, $P I$ prediction interval

${ }^{a}$ See Fig. 1 for a description of dosing regimens to restore nusinersen levels after time since the last dose of 8,16 , or 40 months 


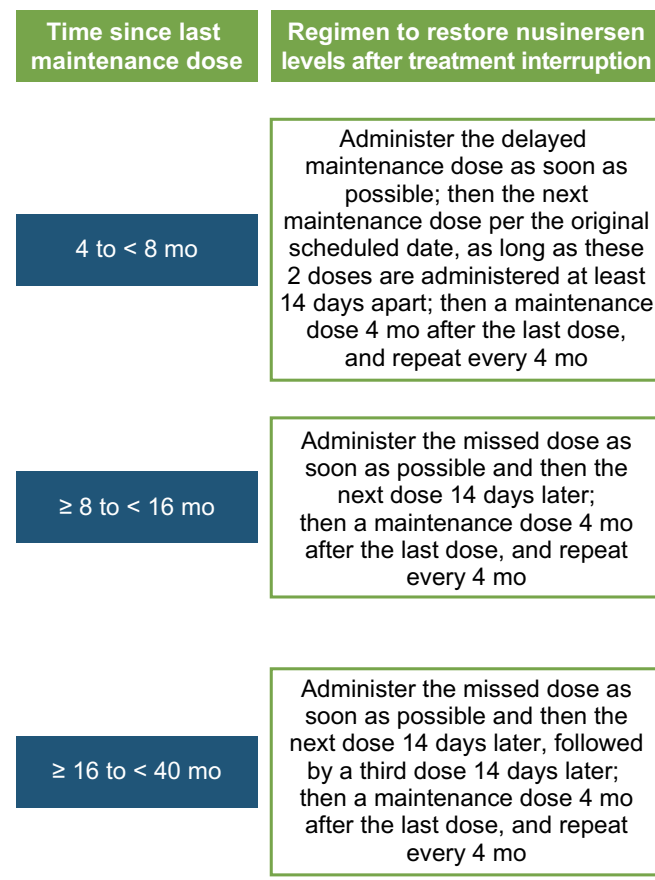
every 4 mo
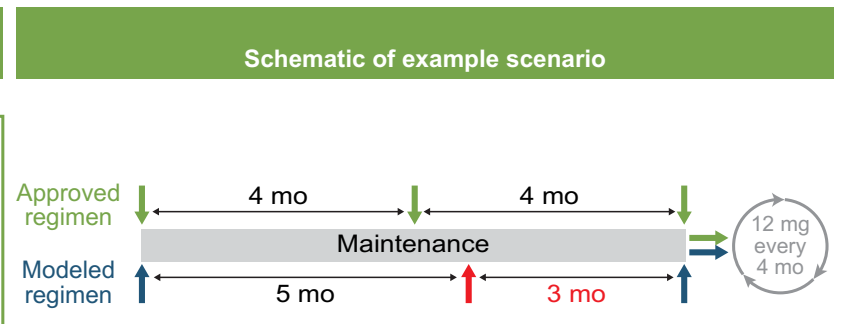

regimen
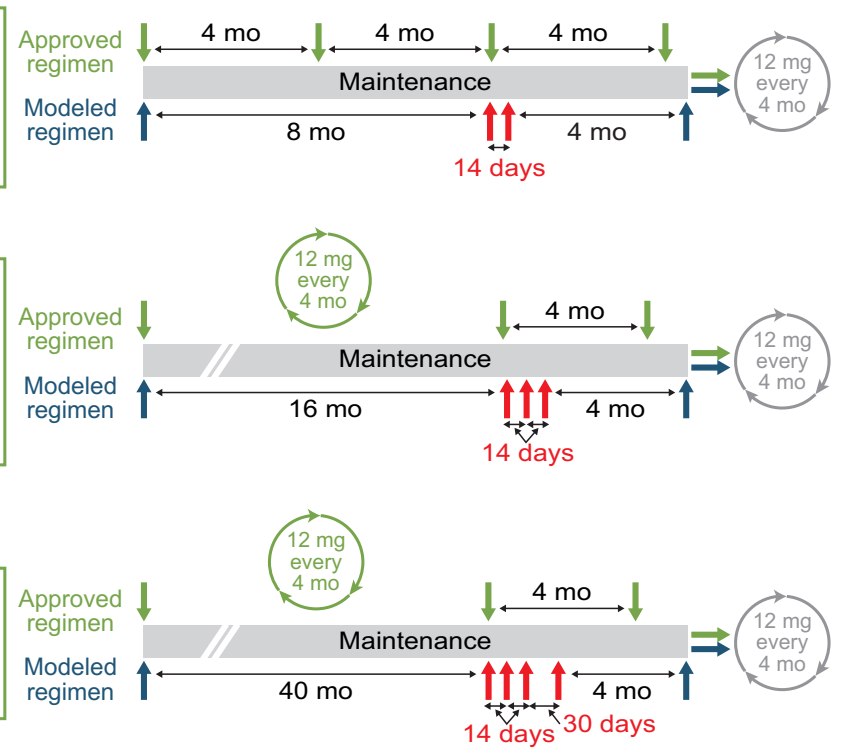

Fig. 1 Scenarios for initiation of nusinersen following different durations of treatment delay/interruption since the last dose of nusinersen. The models for a one-time delay in dosing ( 4 to $<8$ months since last dose) or a single missed dose ( 8 months since last dose) have been described in MacCannell et al. [32]. mo months

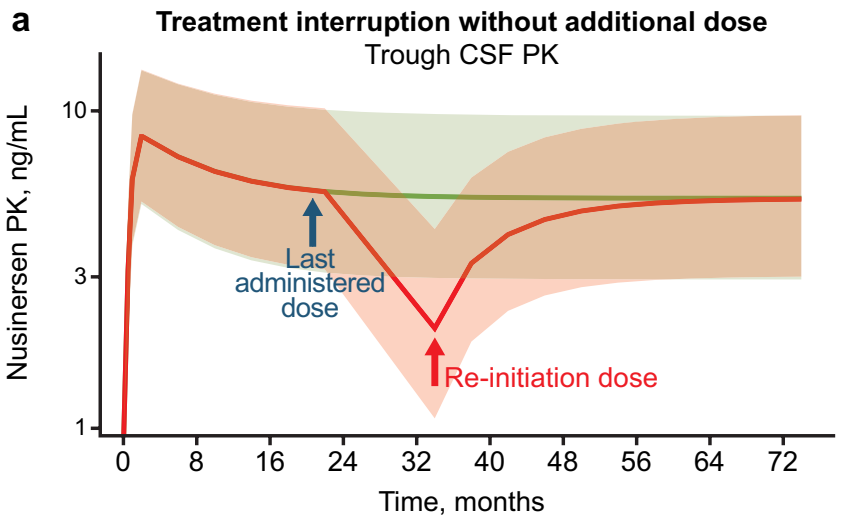

Fig. 2 Administering two doses of nusinersen after a treatment interruption of 12 months since the last dose will rapidly restore CSF levels. a Nusinersen CSF trough concentrations (as predicted by the population pharmacokinetic model) are shown with a 12-month treatment interruption since the last dose, followed by re-initiation of nusinersen with a single dose and every 4 months thereafter. Nusinersen

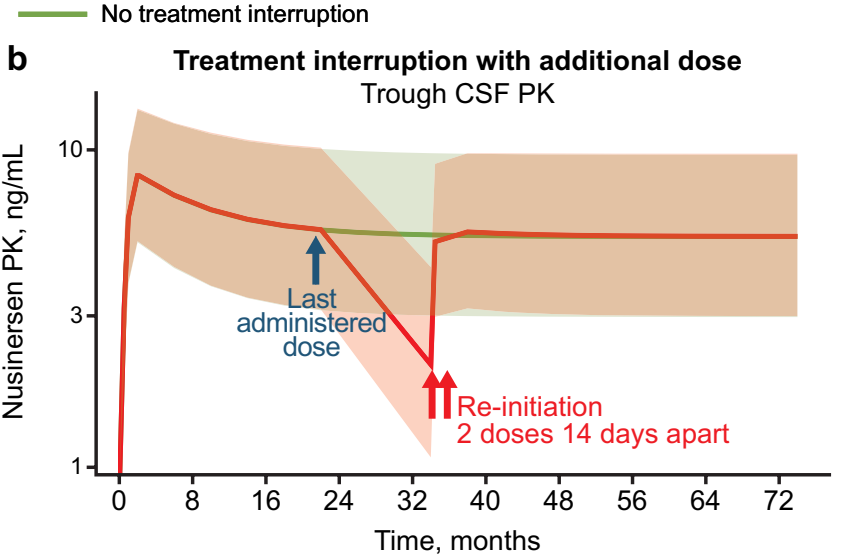

levels will be restored 20 months after re-initiation of nusinersen. b Nusinersen CSF levels after a treatment interruption of 12 months since the last dose (as in a), but with re-initiation of dosing with two doses of nusinersen 14 days apart. Nusinersen CSF levels will be restored approximately 19.5 months earlier than in the scenario in a. $C S F$ cerebrospinal fluid, $P K$ pharmacokinetics 


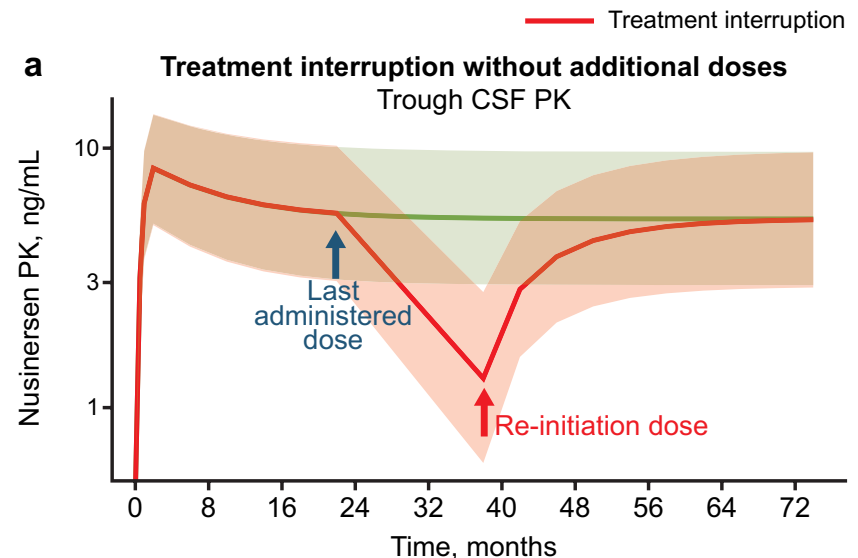

Fig. 3 Administering three doses of nusinersen after a treatment interruption of 16 months since the last dose will restore CSF levels. a Nusinersen CSF trough concentrations (as predicted by the population pharmacokinetic model) are shown with a 16-month treatment interruption since the last dose, followed by re-initiation of nusinersen with a single dose and every 4 months thereafter. Nusinersen

to steady-state concentrations similar to those observed with no interruption in dosing (Fig. 4b). Re-initiation with a single dose of nusinersen $\geq 40$ months after the last dose, followed by the standard maintenance dosing regimen (one dose every 4 months), is predicted to result in suboptimal nusinersen CSF levels (trough concentrations) lasting for approximately 20 months after treatment re-initiation (Fig. 4a). The duration of these suboptimal nusinersen CSF levels remains for approximately 20 months, as before, due to the exponential nature of the increase in $C_{\text {trough }}$. The rate

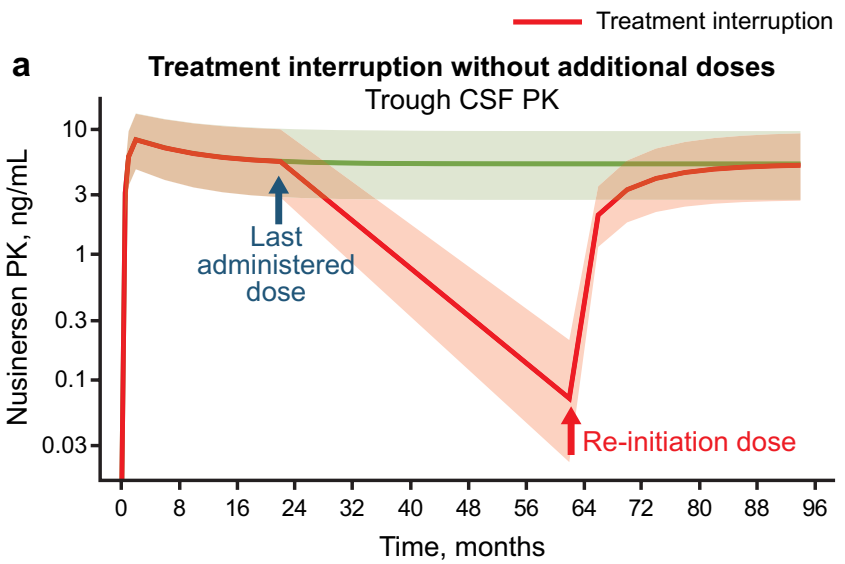

Fig. 4 Administering the entire loading regimen (four doses) after a treatment interruption of $\geq 40$ months since the last dose will restore CSF levels. a Nusinersen CSF trough concentrations (as predicted by the population pharmacokinetic model) are shown with a 40-month treatment interruption since the last dose, followed by re-initiation of nusinersen with a single dose and every 4 months thereafter. Nusinersen levels will be restored 20 months after re-initiation. b Nusin-

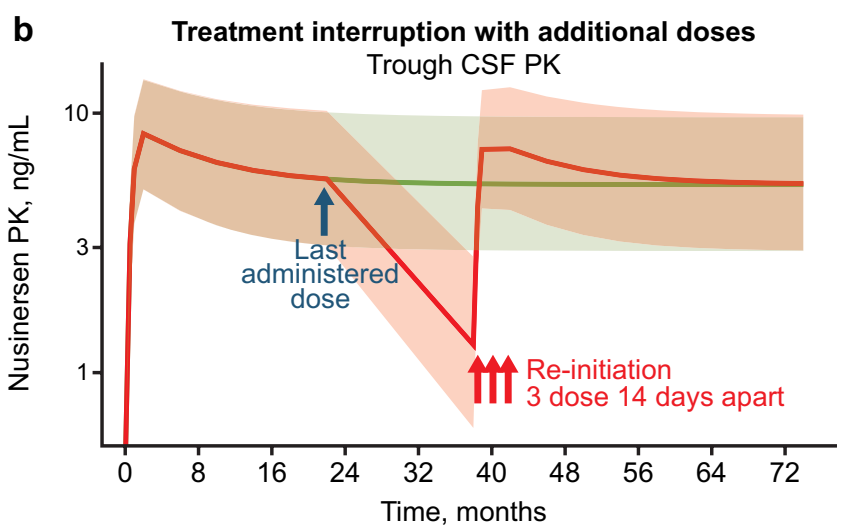

levels will be restored 20 months after re-initiation of nusinersen. b Nusinersen CSF levels after a treatment interruption of 16 months since the last dose (as in a), but with re-initiation of dosing with three doses of nusinersen 14 days apart. Nusinersen CSF levels will be restored approximately 19 months earlier than in the scenario in a. $C S F$ cerebrospinal fluid, $P K$ pharmacokinetics

at which $C_{\text {trough }}$ increases is greatest when it is at its lowest value and is smallest when it is nearest to the steadystate quantity. As a consequence, on a consistent dosing regimen, the time taken to restore steady-state concentrations of nusinersen will generally be approximately five half-lives (20 months). However, although the very low exposure will only have a minor effect on the time taken to restore nusinersen levels, it will impact the total number of doses that must be administered to restore steady-state pharmacokinetics.

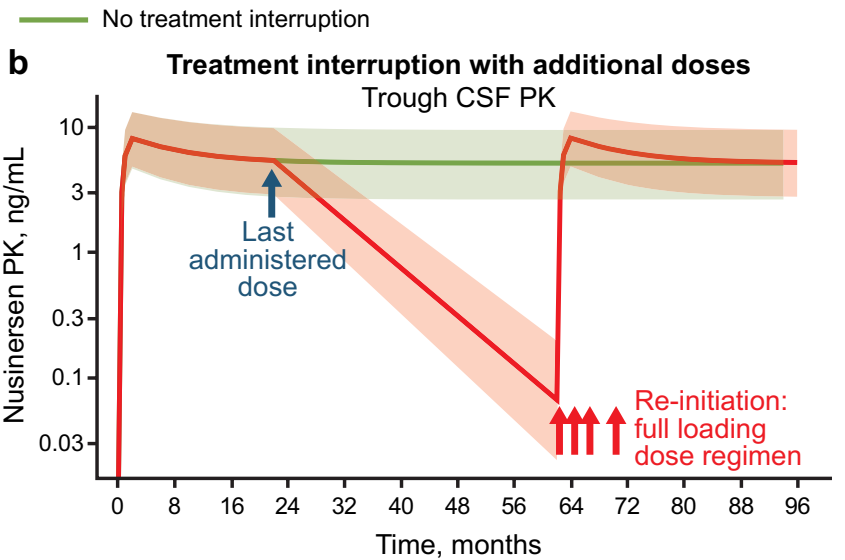

ersen CSF levels after a treatment interruption of $\geq 40$ months since the last dose (as in a), but with re-initiation of dosing with the full loading regimen (three doses of nusinersen 14 days apart followed by a fourth dose 30 days later). Nusinersen CSF levels will be restored approximately 18 months earlier than in the scenario in a. CSF cerebrospinal fluid, $P K$ pharmacokinetics 


\section{Discussion}

Using a population PK model and data from ten clinical trials of nusinersen, we evaluated the impact of longer treatment interruptions during maintenance dosing of nusinersen and modeled which dosing regimen will rapidly restore steady-state CSF concentrations to that expected during the maintenance phase in the absence of an interruption in dosing. This builds on previous work by MacCannell et al. [32], which described shorter treatment interruptions during the maintenance period, as well as delays during the loading period [32].

Given the limited data from clinical trials on delays in treatment and ethical challenges with conducting clinical trials to evaluate the impact of dosing delays, a population PK model has been used for this analysis. The existing PK data from clinical trials are consistent with the predictions of this model, showing levels within the $95 \%$ prediction interval of the model (data not shown). The situations when nusinersen treatment might be interrupted during maintenance dosing include prolonged illness, pandemic-related restrictions, pregnancy, or changing to another therapy and subsequently returning to nusinersen. It is important to ensure that re-initiation of treatment following a treatment interruption can be achieved quickly and safely. The model presented here is not dependent on the reason for the treatment interruption and can therefore further inform any decisions regarding restarting treatment after a prolonged withdrawal from nusinersen. In summary, steady-state nusinersen concentrations will be restored by two doses of nusinersen 14 days apart when it has been $\geq 8$ to $<16$ months since the last maintenance dose, three doses each 14 days apart when it has been $\geq 16$ to $<40$ months since the last maintenance dose, and the full four-dose loading regimen of nusinersen as indicated for treatment-naïve patients (three doses 14 days apart with a fourth dose 30 days later) when it has been $\geq 40$ months since the last maintenance dose (Fig. 1).

Based on the PK modeling, the proposed dosing regimens will lead to nusinersen levels in the CSF similar to those seen with the currently approved regimen, in part because the modeling aims to achieve nusinersen $C_{\text {trough }}$ in CSF similar to those seen with the approved regimen because those levels have been linked to efficacy [34]. Furthermore, the maximum exposures of nusinersen (maximum concentration $\left[C_{\max }\right]$ ), which are often linked to safety outcomes, will remain below those previously attained. Trough concentrations of nusinersen in CSF (measured typically just prior to dosing with nusinersen, i.e., 4 months after the last dose) will remain similar during all proposed regimens. In one scenario with full reloading at 40 months since the last dose, nusinersen $C_{\text {trough }}$ are predicted to be slightly
(2\%) higher than those expected during the initial loading regimen. However, given that nusinersen $C_{\text {trough }}$ CSF are significantly lower (approximately 8600 -fold) than $C_{\max }$, this does not represent overall higher exposure or meaningful difference in $C_{\text {trough }}$. Importantly, the $C_{\max }$ will remain below that previously attained during this and other regimens described in this report.

The modeled dosing regimens are consistent with the currently approved dosing regimen, in that there should be $\geq 14$ days between the first three loading doses. If a fourth dose is required, this dose should be administered 30 or 35 days later, consistent with the current label-approved loading regimen. Although our PK modeling included a fourth dose 30 days after the third dose, our results are similar and also apply to a fourth dose being administered 35 days after the third dose; thus, they are applicable to different regions, which have some differences in this interval as per approved labels. In addition, we do not expect any new safety issues in patients resuming treatment under these dosing regimens.

There are several limitations to our approach described in this report. This model applies only to a one-time interruption and resumption of treatment, followed by an every 4 months dosing regimen. This modeling effort does not address repeated interruptions in dosing. While this work is based on existing clinical trial data, it describes population pharmacokinetics and not any individual outcome. Finally, no patient within our available clinical dataset has had an interruption in treatment $>16$ months. We have assumed an exponential decay in CSF levels throughout the dosing interruption; however, we have limited data as to any nonlinearities in drainage from the CSF or clearance from plasma that may occur at the low levels.

\section{Conclusions}

Prolonged treatment interruptions lead to suboptimal levels of nusinersen in CSF. Our PK modeling indicates the following regimen will lead to optimal restoration of nusinersen CSF levels after treatment interruption: two doses of nusinersen should be administered at 14-day intervals following a treatment interruption of $\geq 8$ to $<16$ months since the last dose, and three doses of nusinersen should be administered at 14-day intervals for treatment interruptions of $\geq 16$ to $<40$ months since the last maintenance dose, with subsequent maintenance dosing every 4 months in both instances. After treatment interruptions of $\geq 40$ months, the full loading dose regimen will restore nusinersen CSF levels.

Acknowledgements Biogen provided funding for medical writing support in the development of this report; Alison Gagnon, $\mathrm{PhD}$, from Excel 
Scientific Solutions provided writing assistance in the development of the first and subsequent drafts based on input from the authors, and Miranda Dixon from Excel Scientific Solutions copy edited and styled the manuscript per journal requirements. The authors had full editorial control of the paper and provided their final approval of all content.

\section{Declarations}

Funding This study was sponsored by Biogen. The open access fee was funded by Biogen.

Conflict of interest Drew MacCannell, Zdenek Berger, and Marta Valente are full-time employees of and hold stock/stock options in Biogen. Janbernd Kirschner received funding for consultancy, educational, and research activities concerning SMA from AveXis/Novartis Gene Therapies, Biogen, Roche, and Scholar Rock. Eugenio Mercuri has participated in advisory boards for SMA studies for AveXis/Novartis Gene Therapies, Biogen, Ionis, Novartis, and Roche; is a principal investigator for ongoing Biogen/Ionis and Roche clinical trials; and has received funding from Famiglie SMA Italy, Italian Telethon, and SMA Europe. Michelle A. Farrar has participated in advisory boards for and received honoraria from Biogen, Roche, and Novartis. Susan T. Iannaccone receives partial salary support from the following grants: the Muscular Dystrophy Association, NeuroNEXT U24NS107176, NIH Wellstone Muscular Dystrophy Center P50HD087351, and Taysha Gene Therapies; receives research support from CureSMA, DoD W81XWH2010293, Parent Project for MD, and industry (Biogen, FibroGen, Novartis, PTC, ReveraGen, Sarepta, and Scholar Rock); and has served on medical advisory boards for Biogen, Novartis, and Sarepta. Nancy L. Kuntz has participated in advisory boards for argenx, Audentes, AveXis/Novartis Gene Therapies, Biogen, Cytokinetics, PTC, Roche, and Sarepta, and received honoraria from Biogen and clinical research funding direct to her institution from Audentes, AveXis/Novartis Gene Therapies, Biogen, and Sarepta. Richard S. Finkel has participated in SMA advisory boards for AveXis/Novartis Gene Therapies, Biogen, Roche, and Scholar Rock; received honoraria from AveXis/Novartis Gene Therapies, Biogen, Elsevier, Excerpta Medica, Roche, and Voyager; received research funding to institution from Biogen and Ionis for conduct of the CS3A, CHERISH, ENDEAR, NURTURE, and SHINE studies, and from AveXis/Novartis Gene Therapies, Cytokinetics, Roche, and Scholar Rock; was a member of the data safety monitoring boards for the AveXis AVX-101 phase I gene transfer study and the Roche Moonfish phase Ib study; serves in an advisory capacity for the nonprofit organizations Cure SMA, SMA Europe, SMA Foundation, and SMA Reach (UK); and receives royalty payments from the Children's Hospital of Philadelphia for licensing fees obtained for use of the CHOP INTEND motor function scale. Francesco Muntoni has participated in advisory boards for Biogen, Dyne Therapeutics, and Pfizer; has been a consultant for AveXis/Novartis Gene Therapies, Biogen, Roche, Santhera, and Sarepta; received grants from the European Commission, Muscular Dystrophy Association USA, Muscular Dystrophy UK, and Medical Research Council; received research funding/investigator grants from Biogen and Sarepta; and has been a principal investigator for Ionis nusinersen trials, the Roche olesoxime and risdiplam trials in SMA, and the Avexis/Novartis gene therapy trial of onasemnogene abeparvovec.

Ethics approval The nusinersen clinical trials were conducted in compliance with the Declaration of Helsinki, the International Council for Harmonisation Good Clinical Practice guidelines, and local regulatory requirements.

Consent to participate Written informed consent was obtained from the parent or legal guardian and the participant, as required by local guidelines and age, for each clinical trial.
Consent for publication Not applicable.

Availability of data and material Requests for data supporting this manuscript should be submitted to the Biogen Clinical Data Request Portal (http://www.biogenclinicaldatarequest.com).

Code availability Not applicable.

Author contributions JK, EM, MAF, STI, NLK, RSF, and FM participated in the collection of data. DM, ZB, and MV participated in the study design and DM conducted the pharmacokinetic analyses. DM, ZB, JK, EM, MAF, STI, NLK, RSF, MV, and FM participated in the analysis and interpretation of data and in drafting and critically revising the manuscript. All authors have read and approved the final submitted paper and agree to be accountable for the work.

Open Access This article is licensed under a Creative Commons Attribution-NonCommercial 4.0 International License, which permits any non-commercial use, sharing, adaptation, distribution and reproduction in any medium or format, as long as you give appropriate credit to the original author(s) and the source, provide a link to the Creative Commons licence, and indicate if changes were made. The images or other third party material in this article are included in the article's Creative Commons licence, unless indicated otherwise in a credit line to the material. If material is not included in the article's Creative Commons licence and your intended use is not permitted by statutory regulation or exceeds the permitted use, you will need to obtain permission directly from the copyright holder. To view a copy of this licence, visit http://creativecommons.org/licenses/by-nc/4.0/.

\section{References}

1. Darras BT. Spinal muscular atrophies. Pediatr Clin North Am. 2015;62(3):743-66. https://doi.org/10.1016/j.pcl.2015.03.010.

2. Lunn MR, Wang CH. Spinal muscular atrophy. Lancet. 2008;371(9630):2120-33. https://doi.org/10.1016/S01406736(08)60921-6.

3. Prior TW, Snyder PJ, Rink BD, Pearl DK, Pyatt RE, Mihal DC, et al. Newborn and carrier screening for spinal muscular atrophy. Am J Med Genet A. 2010;152A(7):1608-16. https://doi.org/10. 1002/ajmg.a.33474.

4. D'Amico A, Mercuri E, Tiziano FD, Bertini E. Spinal muscular atrophy. Orphanet J Rare Dis. 2011;6:71. https://doi.org/10.1186/ 1750-1172-6-71.

5. Monani UR, Lorson CL, Parsons DW, Prior TW, Androphy EJ, Burghes AH, et al. A single nucleotide difference that alters splicing patterns distinguishes the SMA gene SMN1 from the copy gene SMN2. Hum Mol Genet. 1999;8(7):1177-83. https://doi.org/ 10.1093/hmg/8.7.1177.

6. Finkel R, Bertini E, Muntoni F, Mercuri E, ENMC SMA Workshop Study Group. 209th ENMC International Workshop: outcome measures and clinical trial readiness in spinal muscular atrophy 7-9 November 2014, Heemskerk, The Netherlands. Neuromuscul Disord. 2015;25(7):593-602. https://doi.org/10.1016/j. nmd.2015.04.009.

7. Kolb SJ, Coffey CS, Yankey JW, Krosschell K, Arnold WD, Rutkove SB, NeuroNEXT Clinical Trial Network on behalf of the NN101 SMA Biomarker Investigators, et al. Natural history of infantile-onset spinal muscular atrophy. Ann Neurol. 2017;82(6):883-91. https://doi.org/10.1002/ana.25101.

8. Farrar MA, Park SB, Vucic S, Carey KA, Turner BJ, Gillingwater $\mathrm{TH}$, et al. Emerging therapies and challenges in spinal muscular atrophy. Ann Neurol. 2017;81(3):355-68. https://doi.org/10.1002/ ana. 24864 . 
9. Messina S, Sframeli M. New treatments in spinal muscular atrophy: positive results and new challenges. J Clin Med. 2020;9(7):2222. https://doi.org/10.3390/jcm9072222.

10. Biogen. SPINRAZA (nusinersen) injection, for intrathecal use. 2020. Available from: www.spinraza.com/content/dam/comme $\mathrm{rcial} /$ specialty/spinraza/caregiver/en_us/pdf/spinraza-prescribing-information.pdf. Accessed 25 June 2020.

11. European Medicines Agency. Spinraza $12 \mathrm{mg}$ solution for injection. 2017. Available from: http://www.ema.europa.eu/docs/en GB/document_library/EPAR_-_Product_Information/human/ 004312/WC500229704.pdf. Accessed 25 June 2020.

12. Havens MA, Hastings ML. Splice-switching antisense oligonucleotides as therapeutic drugs. Nucleic Acids Res. 2016;44(14):6549-63. https://doi.org/10.1093/nar/gkw533.

13. Hua Y, Sahashi K, Hung G, Rigo F, Passini MA, Bennett CF, et al. Antisense correction of SMN2 splicing in the CNS rescues necrosis in a type III SMA mouse model. Genes Dev. 2010;24(15):1634-44. https://doi.org/10.1101/gad.1941310.

14. Rigo F, Hua Y, Krainer AR, Bennett CF. Antisense-based therapy for the treatment of spinal muscular atrophy. J Cell Biol. 2012;199(1):21-5. https://doi.org/10.1083/jcb.201207087.

15. Finkel RS, Chiriboga CA, Vajsar J, Day JW, Montes J, De Vivo DC, et al. Treatment of infantile-onset spinal muscular atrophy with nusinersen: a phase 2, open-label, dose-escalation study. Lancet. 2016;388(10063):3017-26. https://doi.org/10.1016/S01406736(16)31408-8.

16. Finkel RS, Mercuri E, Darras BT, Connolly AM, Kuntz NL, Kirschner J, ENDEAR Study Group, et al. Nusinersen versus sham control in infantile-onset spinal muscular atrophy. N Engl J Med. 2017;377(18):1723-32. https://doi.org/10.1056/NEJMo a1702752.

17. Acsadi G, Crawford TO, Muller-Felber W, Shieh PB, Richardson R, Natarajan N, et al. Safety and efficacy of nusinersen in spinal muscular atrophy: the EMBRACE study. Muscle Nerve. 2021;63(5):668-77. https://doi.org/10.1002/mus.27187.

18. Chiriboga CA, Swoboda KJ, Darras BT, Iannaccone ST, Montes J, De Vivo DC, et al. Results from a phase 1 study of nusinersen (ISIS-SMN(Rx)) in children with spinal muscular atrophy. Neurology. 2016;86(10):890-7. https://doi.org/10.1212/WNL.00000 00000002445.

19. Mercuri E, Darras BT, Chiriboga CA, Day JW, Campbell C, Connolly AM, CHERISH Study Group, et al. Nusinersen versus sham control in later-onset spinal muscular atrophy. N Engl J Med. 2018;378(7):625-35. https://doi.org/10.1056/NEJMoa1710504.

20. Darras BT, Chiriboga CA, Iannaccone ST, Swoboda KJ, Montes J, Mignon L, ISIS-396443-CS2/ISIS-396443-CS12 Study Groups, et al. Nusinersen in later-onset spinal muscular atrophy: long-term results from the phase 1/2 studies. Neurology. 2019;92(21):e2492506. https://doi.org/10.1212/WNL.0000000000007527.

21. Finkel R, Castro D, Farrar M, Tulinius M, Krosschell K, Saito $\mathrm{K}$, on behalf of the SHINE Study Group, et al. Nusinersen in infantile-onset spinal muscular atrophy: results from longer-term treatment from the open-label SHINE extension study. Neuromuscul Disord. 2020;30(Suppl. 1):S124. https://doi.org/10.1016/j. nmd.2020.08.265

22. Mercuri E, Darras B, Chiriboga C, Farrar M, Kirschner J, Kuntz N, on behalf of the SHINE Study Group, et al. Longer-term treatment with nusinersen: results in later-onset spinal muscular atrophy from the SHINE study. Neuromuscul Disord. 2020;30(Suppl. 1):S121. https://doi.org/10.1016/j.nmd.2020.08.257.
23. De Vivo DC, Bertini E, Swoboda KJ, Hwu WL, Crawford TO, Finkel RS, NURTURE Study Group, et al. Nusinersen initiated in infants during the presymptomatic stage of spinal muscular atrophy: interim efficacy and safety results from the phase 2 NURTURE study. Neuromuscul Disord. 2019;29(11):842-56. https:// doi.org/10.1016/j.nmd.2019.09.007.

24. Darras BT, Farrar MA, Mercuri E, Finkel RS, Foster R, Hughes SG, et al. An integrated safety analysis of infants and children with symptomatic spinal muscular atrophy (SMA) treated with nusinersen in seven clinical trials. CNS Drugs. 2019;33(9):91932. https://doi.org/10.1007/s40263-019-00656-w.

25. Hagenacker T, Wurster CD, Günther R, Schreiber-Katz O, Osmanovic A, Petri S, et al. Nusinersen in adults with $5 \mathrm{q}$ spinal muscular atrophy: a non-interventional, multicentre, observational cohort study. Lancet Neurol. 2020;19(4):317-25. https://doi.org/ 10.1016/S1474-4422(20)30037-5.

26. Szabó L, Gergely A, Jakus R, Fogarasi A, Grosz Z, Molnár MJ, et al. Efficacy of nusinersen in type 1,2 and 3 spinal muscular atrophy: real world data from Hungarian patients. Eur J Paediatr Neurol. 2020;27:37-42. https://doi.org/10.1016/j.ejpn.2020.05. 002.

27. Walter MC, Wenninger S, Thiele S, Stauber J, Hiebeler M, Greckl E, et al. Safety and treatment effects of nusinersen in longstanding adult 5q-SMA type 3 : a prospective observational study. J Neuromuscul Dis. 2019;6(4):453-65. https://doi.org/10.3233/ JND-190416.

28. Duong T, Wolford C, McDermott MP, Macpherson CE, Pasternak A, Glanzman AM, et al. Nusinersen treatment in adults with spinal muscular atrophy. Neurol Clin Pract. 2021;11(3):e317-27. https:// doi.org/10.1212/CPJ.0000000000001033.

29. Elsheikh B, Severyn S, Zhao S, Kline D, Linsenmayer M, Kelly K, et al. Safety, tolerability, and effect of nusinersen in non-ambulatory adults with spinal muscular atrophy. Front Neurol. 2021;12: 650532. https://doi.org/10.3389/fneur.2021.650532.

30. Elsheikh B, Severyn S, Zhao S, Kline D, Linsenmayer M, Kelly $\mathrm{K}$, et al. Safety, tolerability, and effect of nusinersen treatment in ambulatory adults with 5q-SMA. Front Neurol. 2021;12: 650535. https://doi.org/10.3389/fneur.2021.650535.

31. Maggi L, Bello L, Bonanno S, Govoni A, Caponnetto C, Passamano L, et al. Nusinersen safety and effects on motor function in adult spinal muscular atrophy type 2 and 3. J Neurol Neurosurg Psychiatry. 2020;91(11):1166-74. https://doi.org/10.1136/ jnnp-2020-323822.

32. MacCannell D, Berger Z, East L, Mercuri E, Kirschner J, Muntoni $\mathrm{F}$, et al. Population pharmacokinetics-based recommendations for a single delayed or missed dose of nusinersen. Neuromuscul Disord. 2021;31(4):310-8. https://doi.org/10.1016/j.nmd.2021.02. 014.

33. Wickham H. Elegant graphics for data analysis. New York (NY): Springer; 2016.

34. Ryan M, Finkel R, Pascual Pascual S, Day J, Mercuri E, De Vivo $\mathrm{D}$, et al. Scientific rationale for a higher dose of nusinersen. Neuromuscul Disord. 2021;31(Suppl. 1):S131. https://doi.org/10. 1016/j.nmd.2021.07.294. 


\section{Authors and Affiliations}

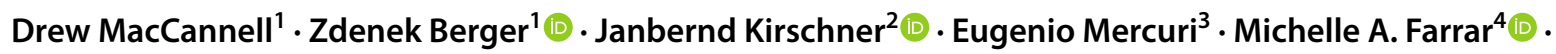
Susan T. Iannaccone ${ }^{5} \cdot$ Nancy L. Kuntz $^{6}\left(\mathbb{D} \cdot\right.$ Richard S. Finkel $^{7} \cdot$ Marta Valente $^{8} \cdot$ Francesco Muntoni $^{9}$ (i)

1 Biogen, 300 Binney Street, Cambridge, MA 02142, USA

2 Department of Neuropediatrics, Faculty of Medicine, University Hospital Bonn, Bonn, Germany

3 Department of Paediatric Neurology, Università Cattolica del Sacro Cuore, Rome, Italy

4 Department of Neurology, Sydney Children's Hospital and School of Women's and Children's Health, UNSW Medicine, Sydney, NSW, Australia

5 Department of Pediatrics, University of Texas Southwestern Medical Center, Dallas, TX, USA
6 Department of Pediatrics, Ann \& Robert H. Lurie Children's Hospital of Chicago, Chicago, IL, USA

7 Center for Experimental Neurotherapeutics, St. Jude Children's Research Hospital, Memphis, TN, USA

8 Biogen, Baar, Switzerland

9 Dubowitz Neuromuscular Centre, NIHR Great Ormond Street Hospital Biomedical Research Centre, UCL Great Ormond Street Institute of Child Health and Great Ormond Street Hospital for Children NHS Foundation Trust, London, UK 